\title{
ACTION RESEARCH: THEORY AND PRACTICE IN ENGLISH PRE-SERVICE TEACHERS
}

\author{
Neni Marlina \\ Junjun M. Ramdani \\ Melisa Sri \\ Siliwangi University, Indonesia \\ kunee_m@yahoo.com \\ junjunmuhamad@unsil.ac.id \\ melisahandri@yahoo.com
}

\begin{abstract}
The action research in English as a Foreign Language (EFL) classroom aims to enhance development of quality teaching and learning process contributing not only to the quality of EFL teachers in handling the process of teaching learning but also to the quality of the students in learning English. This study aims at analyzing the phenomenon of how pre service teachers carry out action research as their final Project. It is conducted in English Education Department, one of universities in Indonesia. Three of the students' papers were selected randomly to analyze. Review of documents and questionnaires were employed as data collection in this study. Having gathered the data, they were holistically analyzed as a case study occurring in English Education Department. The results indicated there were several cases happened. First, the pre service teachers did not comprehend holistically the notion of action research. Second, background of the study was not elaborated completely showing evidences of the study. Third, it is also unclear how all problem indicators were improved rationally using particular techniques or method. Fourth, they did not also comprehensively collect and analyze the data. The last, reporting the research project focused only on the quantitative data rather than qualitative one. Therefore, both researchers and supervisors are necessary to possess the whole understanding toward the type of the research chosen. Enriching literature reviews will enhance their literacy in order to achieve a better implementation in conducting action research.
\end{abstract}

Keywords: action research, case study, pre-service teacher

\section{INTRODUCTION}

The classroom action research in EFL classroom has great roles to the development of quality teaching and learning process. It contributes not only to the quality of EFL teachers in handling the process of teaching learning but also to the quality of the students in learning English. By implementing this research, the teachers are trained to be able to carefully observe students' 
Marlina, Ramdani, Sri, Action Research: Theory and Practice in English...

behaviors and their potential problems, modify their teaching practices and evaluate the result. Koshy (2005: 2) defines action research as an enquiry, undertaken with rigor and understanding so as to constantly refine practice; the emerging evidence-based outcomes will then contribute to the researching practitioner's continuing professional development. It is obviously regarded that this research assists teachers to improve their teaching practices to reach good quality of education.

The implementation of the classroom action research (CAR) is also introduced to the pre service teachers who are prepared to be English teachers who will engage with the school environment, classroom situation, students' behavior and learning process besides it is introduced as one of the kind of research that can be gone through when they would like to accomplish their thesis project/final project. They are expected to have good comprehension about the use of action research to improve their capability of language teaching practices and encourage them to possess their critical thinking towards the development of language learning outcomes. Levin and Rock (2003) summarize the advantages of the research for the teachers. Some of them are that action research promotes continuous learning (Boyer, 1990; Rock, 1997; Shalaway, 1990), revitalizes teachers' practice, and motivates teachers by improving their self-confidence as professionals (Lomax, 1995; Reading/Learning in Secondary Schools Subcommittee of the International Reading Association, 1989; Rock, 1997). Thus, to improve their capability of teaching is to involve them in doing the action research in the classroom.

However, the preliminary observation indicated that there were still many pre service teachers who still did not comprehend well the implementation of action research for their improvement in their teaching practices. They tended to apply the action research only for fulfilling the requirement for getting bachelor degree without focusing their research on what problem and how to overcome it occurring in their field. Besides, they had limited knowledge about how to implement the steps of conducting the action research; they were sometimes confused about differentiating the action research and experiment research; in analyzing the data, they tended to focus more on quantitative data than qualitative one. Most of them regarded that the 
success of teaching could only be obtained if the students reached the minimum criteria of success; and observation was focused more on the weaknesses of the process of teaching learning. Those problems affected to the improvement of teaching and learning process.

Regarding those problems, this study was necessary to conduct to clarify how the classroom action research in pre service teachers is implemented. It would support the quality of the pre-service teachers to carry out this research. Therefore, they are going to be professional when they become teachers.

\section{RESEARCH METHODS}

This part explains three crucial facets in conducting the research such as: 1) research methodology, 2) data collection, and 3) technique of analyzing the data. A case study is selected as the research methodology. According to Yin (2003) in general, case studies are the preferred strategy when "how" or "why" questions are being posed, when the investigator has little control over events, and when the focus is on a contemporary phenomenon within some real-life context. Additionally, Ary, et. al. (2010) say that case studies provide an in-depth description of a single unit. The unit can be an individual, a group, a site, a class, so on. This research focused on the fourth grade student as pre service teachers in English Education Department, a university in Indonesia. Three papers of the students' final project had been selected randomly to be analyzed.

Review of documents and questionnaire were employed as data collection. Having completed the collection of the data, it was analyzed holistically to reach the entire cases occurring in the implementation of classroom action research in pre service teachers, such as, elaborating; 1) background and formulation of the problems, 2) data collection; 3) analyzing the data; 4) the result of qualitative and quantitative data as research result. This study was conducted in August - November 2015. 
Marlina, Ramdani, Sri, Action Research: Theory and Practice in English...

\section{RESEARCH FINDING AND DISCUSSION}

Research Finding

This case study pointed out how pre - service teachers implemented classroom action research as their final project to achieve their bachelor degree. Four parts of the analysis were elaborated as the research findings, such as; 1) background and formulation of the problems, 2) data collection; 3) analyzing the data; 4) the result of qualitative and quantitative data as research result. Each of this part was analyzed from three different students' final project) and drawn in the following description.

Table 4.1. The Analysis of CAR's Background in the Pre-Service

Teachers

\begin{tabular}{|c|c|c|}
\hline NO. & RESEARCH TITLE & ANALYSIS FOCUS AND DESCRIPTION \\
\hline & $\begin{array}{l}\text { IMPROVING } \\
\text { STUDENTS' } \\
\text { READING } \\
\text { COMPREHENSION } \\
\text { THROUGH } \\
\text { STUDENT TEAMS } \\
\text { ACHIEVEMENT } \\
\text { DIVISIONS (STAD) } \\
\text { TECHNIQUE }\end{array}$ & $\begin{array}{l}\text { Background } \\
\text { In his research, he stated ideal condition, the } \\
\text { problems the indicators faced by the students } \\
\text { on reading comprehension, such as; 1) } \\
\text { difficulty in finding specific information } \\
\text { (implicit and explicit information); 2) obtaining } \\
\text { main ideas of the text; and 3) searching } \\
\text { information in each paragraph. He also drew } \\
\text { the causes why it occurred both from the } \\
\text { teacher and students. Finally he proposed } \\
\text { STAD as the solution to cope with all problems } \\
\text { appearing in this class because it is } \\
\text { motivating, and the students can ask one } \\
\text { another related to learning problems } \\
\text { appearing during teaching and learning } \\
\text { process. } \\
\text { Result of analysis } \\
\text { 1. He only stated three indicators of reading as } \\
\text { the problems of his research such as } \\
\text { getting ideas, referential and inferential } \\
\text { meaning, however, there was no clear data } \\
\text { (pre-test) instrument showing that the } \\
\text { students face those indicators. Something } \\
\text { which is still questionable is that how about } \\
\text { other reading indicators? For example, } \\
\text { reference, vocabulary (synonym and } \\
\text { antonym). In other words, he did not } \\
\text { comprehensively explain the problem } \\
\text { indicators of reading comprehension faced } \\
\text { by the students. } \\
\text { 2. He proposed the solution by STAD because } \\
\text { its strengths and advantages, however, he }\end{array}$ \\
\hline
\end{tabular}


did not explore how each the student of each member of the group motivated one another. Can all students motivate one another? It is still unclear how STAD worked as a technique to motivate the students to learn. Additionally, it is also unclear how all indicators are improved by implementing STAD. When he thought that the students can ask each other, the problems of reading faced by the students have been solved. In contrary, the learning problems can still exist because all leaders of each group have different skills and knowledge capacity. How if some of them did not comprehensively understand what the text about, it means that STAD cannot be a solution for this case. When he added that teacher can help the students if there are some problems, in other words, what made the students learn was not STAD but teacher's explanation. In conclusion, it is still bias how all indicators are improved by STAD.

IMPROVING

STUDENTS'

SPEAKING ABILITY

USING

INFORMATION GAP

TECHNIQUE
This research was conducted because there were several problems the students face in learning speaking. The problems the students had were; a) limited vocabulary, b) limited knowledge of rules, c) less capability in pronunciation, d) and, difficult to express idea.

\section{Result of Analysis}

1. Regarding to the problems above, she didn't clarify why the problems in speaking occurred. It was not explained very clearly or even showed how she could get the data what the students' problems while learning speaking.

2. The researcher only proposed Information Gap to solve the problems. It was not clearly argued how and why this technique could solve the problem indicators in learning speaking. She only stated that this technique helps the students share information, and builds their interest in learning.
There were several problems the students faced when they learned speaking were argued by the researcher. She stated that they low 
Marlina, Ramdani, Sri, Action Research: Theory and Practice in English...

\author{
BY USING ROLE \\ PLAY TECHNIQUE
}

ability in mastering vocabulary, fluency and comprehension causing their KKM (criteria of minimum completion) is under the standard. It was not clarified what made the students' faced those problems.

\section{Result of Analysis}

She emphasized that role play is suitable to solve the problems. It is also an effective technique to animate the teaching and learning atmosphere, to arouse the interests of learners, and to make the language acquisition impressive. Further, It can stimulate them to be active, attractive, effective and enjoyable (it was not described that the students also face those problems)

Although there were several advantages that she claimed that this technique helped the students in learning process or in learning speaking, it was not clarified clearly how and why role play could solve the problems the students face, such as how it could solve their limited vocabulary, or helped them to be fluent in speaking.

The Table 4.1. shows that background of action research captures what occurred in the classroom as the pre-luminary study. It covers ideal condition the real condition of the class, causes why the obstacles exist, and solution. These schemes are ideally supported by the actual data obtained in the preluminary study or pre-research which can be verified. Dealing with the phenomena in the pre-service teachers at UNSIL on conducting this research, they tend to provide the real condition within the less data source which can support their statements in the background of the study. Moreover, it seems the problem indicators of each study seem not to be comprehensively analyzed. For example, research no. 1, it is only stated that there are three problem indicators faced by the students in reading comprehension. However, he did not analyze other reading indicators which are still possibly possessed by the students. It is still doubtful because there are no data supporting his statement. Therefore, they need to point out the background clearly and accurately. Analyzing problem indicators must be done comprehensively through the pre-research conducted. 


\section{Edulite}

Journal of English Education, Literature, and Culture

Volume 1, Number 2, August 2016

In addition, the next part of the background to write and explore is some causes why the problems are faced by the students. Generally, it can come from three different angles, such as; 1) teacher; 2) students; and 3) classroom condition. The exploration is able to be carried out through the different angles as stated previously in order to provide the significance of the action research conducted. There is only one study showing why the problems occurred in the classes they handled. It means the two studies, in this case, are not analyzed objectively which make the background less complete.

The crucial section of background in action research is solution, how it copes with all problems in the classroom. They mostly do not describe how technique or method can solve the problems faced by the students. More importantly, it is not clearly explained how all indicators are improved rationally by the particular technique or method chosen. In other words, the rationales proposed by all pre-service teachers cannot guarantee the enhancement of the students' English skill and the class condition. As a result, the final reflection of all studies is still bias dealing with the way they report.

Table 4.2. The Analysis of CAR's Data Collection in the Pre-Service Teachers

\begin{tabular}{|c|c|c|}
\hline NO. & RESEARCH TITLE & ANALYSIS FOCUS AND DESCRIPTION \\
\hline & $\begin{array}{l}\text { IMPROVING } \\
\text { STUDENTS' } \\
\text { READING } \\
\text { COMPREHENSION } \\
\text { THROUGH } \\
\text { STUDENT TEAMS } \\
\text { ACHIEVEMENT } \\
\text { DIVISIONS (STAD) } \\
\text { TECHNIQUE }\end{array}$ & $\begin{array}{l}\text { Data Collection } \\
\text { To collect the data of his research he used } \\
\text { observation and test. } \\
\text { Result of Analysis } \\
\text { To collect the data in action research, there are } \\
\text { three points the researcher needs to do such } \\
\text { as; 1) experiencing 2) enquiring; and 3) } \\
\text { examining. What he collected was experiencing } \\
\text { (observing) and examining (test). In other } \\
\text { words, he missed one of the data collections of } \\
\text { his research which can support to elaborate } \\
\text { the improvement of the class }\end{array}$ \\
\hline & & $\begin{array}{l}\text { condition. The missing part of his data } \\
\text { collection is related to the class condition, and } \\
\text { the data are obtained from the students as the } \\
\text { subject of the study. It can be done by } \\
\text { interview, internet based interview, written } \\
\text { responses, etc. It can be concluded this } \\
\text { research cannot show other sources of the } \\
\text { data to answer the action hypothesis. }\end{array}$ \\
\hline
\end{tabular}


Marlina, Ramdani, Sri, Action Research: Theory and Practice in English...

\begin{tabular}{|c|c|}
\hline $\begin{array}{l}\text { IMPROVING } \\
\text { STUDENTS' } \\
\text { SPEAKING ABILITY } \\
\text { USING } \\
\text { INFORMATION GAP } \\
\text { TECHNIQUE }\end{array}$ & $\begin{array}{l}\text { Data Collection } \\
\text { Observation and Speaking test are used to } \\
\text { collect the data. } \\
\text { Result of Analysis } \\
\text { Observation done in this research covers } \\
\text { preparation, presentation, execution/methods, } \\
\text { personal characteristics, and teacher/student } \\
\text { interaction based on Douglas theory. } \\
\text { Speaking Test was held in the type of } \\
\text { monologue. } \\
\text { As stated above that three steps that need to } \\
\text { be through in gathering the data consisting } \\
\text { experiencing, enquiring and examining. But it } \\
\text { is the same as the first researcher that the } \\
\text { researcher in doing this research missed the } \\
\text { second step, enquiring, in which the } \\
\text { researcher didn't involve the students' } \\
\text { responses about the implementation of the } \\
\text { technique she used in teaching speaking. }\end{array}$ \\
\hline $\begin{array}{l}\text { IMPROVING } \\
\text { STUDENTS' } \\
\text { SPEAKING ABILITY } \\
\text { BY USING ROLE } \\
\text { PLAY TECHNIQUE }\end{array}$ & $\begin{array}{l}\text { Data Collection } \\
\text { Test and observation are used to collect the } \\
\text { data. } \\
\text { Result of Analysis } \\
\text { From observation used for collecting the } \\
\text { qualitative data, this observation was not } \\
\text { clearly described what aspects are observed. It } \\
\text { is only generalized that the researcher } \\
\text { observed the learning process when Role Play } \\
\text { technique was implemented. } \\
\text { Test of speaking was conducted by using } \\
\text { dialogue }\end{array}$ \\
\hline & $\begin{array}{l}\text { orally. } \\
\text { From the data collection, it is revealed that } \\
\text { this research also missed the enquiring data } \\
\text { which is obtained from the students' } \\
\text { responses. }\end{array}$ \\
\hline
\end{tabular}

Based on table 4.2. pre-service teacher only carried out two data collections, observation and test. Meanwhile, various ways to collect the data can be carried out by the researchers, like, observation, test, interview, questionnaire, semi structured interview, informal face to face interview, etc. proposed by experts. It means they miss the one essential data collection, enquiring. It can be obtained from the students' responses. It is necessary to do because the teachers cannot subjectively report their research, action research, without the data from the students. The interview or written 


\section{EduLite}

Journal of English Education, Literature, and Culture

Volume 1, Number 2, August 2016

response is simply conducted. They only ask the students' experience during the treatment in all cycles conducted. From this data, it is expected that conducting action research can enhance both the students' English skill and the class condition. To conclude this point, the data collection is less complete which can support the elaboration of the research report.

Table 4.3. The Analysis of CAR's Data Analysis in the Pre-Service Teachers

\begin{tabular}{|c|c|c|}
\hline NO. & RESEARCH T & ANALYSIS FOCUS AND DESCRIPTION \\
\hline & $\begin{array}{l}\text { IMPROVING } \\
\text { STUDENTS' } \\
\text { READING } \\
\text { COMPREHENSION } \\
\text { THROUGH } \\
\text { STUDENT TEAMS } \\
\text { ACHIEVEMENT } \\
\text { DIVISIONS (STAD) } \\
\text { TECHNIQUE }\end{array}$ & $\begin{array}{l}\text { Technique of Analyzing the Data } \\
\text { He divided the data as quantitative and } \\
\text { qualitative one to analyze. Besides, he used } \\
\text { two different way to analyze both quantitative } \\
\text { data and qualitative one. To analyze } \\
\text { quantitative data he used descriptive statistics } \\
\text { in which he draws mean of the test's result to } \\
\text { show the progress of the students' reading } \\
\text { comprehension. To analyze qualitative data he } \\
\text { used Burns'theory (2010:104-105). } \\
\text { Result of Analysis } \\
\text { He completely analyzed the data both } \\
\text { quantitatively and qualitatively. In conclusion, } \\
\text { the steps of the data analysis have been } \\
\text { conducted well. }\end{array}$ \\
\hline & $\begin{array}{l}\text { IMPROVING } \\
\text { STUDENTS' } \\
\text { SPEAKING ABILITY } \\
\text { USING } \\
\text { INFORMATION GAP } \\
\text { TECHNIQUE }\end{array}$ & $\begin{array}{l}\text { Technique of Analyzing the Data } \\
\text { The data obtained are in the form of } \\
\text { quantitative and qualitative data. Quantitative } \\
\text { data are obtained from the students' speaking } \\
\text { test result which is analyzed using descriptive } \\
\text { statistics. Qualitative data are from the result } \\
\text { of observation covering five aspects, such as, } \\
\text { preparation, presentation, } \\
\text { execution/methods, personal characteristics, } \\
\text { and teacher/student interaction. (Douglas, } \\
\text { 2001) Result of Analysis the dualitative data, the } \\
\text { In analyzing the data } \\
\text { researcher didn't analyze the dat data } \\
\text { appropriately. She only described that the } \\
\text { data are only analyzed by using categorizing } \\
\text { and coding. }\end{array}$ \\
\hline & $\begin{array}{l}\text { IMPROVING } \\
\text { STUDENTS' } \\
\text { SPEAKING ABILITY }\end{array}$ & $\begin{array}{l}\text { Technique of Analyzing the Data } \\
\text { Students' speaking test results are analyzed } \\
\text { by using descriptive statistics in which he }\end{array}$ \\
\hline
\end{tabular}


Marlina, Ramdani, Sri, Action Research: Theory and Practice in English...

$\begin{array}{ll}\text { BY USING ROLE } & \text { draws mean of the test's result. } \\ \text { PLAY TECHNIQUE } & \begin{array}{l}\text { Observation result is analyzed by using three } \\ \text { steps consisting data reduction, data display, } \\ \text { and conclusion drawing/verification. }\end{array}\end{array}$

Table 4.3. portyared the way to analyse the data in their research. To analyze the quantitative one, they implement the same stages, by descriptive statistics, which can display the improvement of the students' English skill after the treatments had been done in each cycle conducted, two cycles conducted for each research. However, different steps to analyze the qualitative data are shown in this study. Each researcher, pre-service teacher chose various theories as data analysis technique, except the second researcher. There was no clear description on how the qualitative data were analyzed. As a result, what has been described in every cycle was not based on the data analysis.

Table 4.4. The Analysis of CAR's Report in the Pre-Service Teachers

\begin{tabular}{|c|c|c|}
\hline NO. & RESEARCH TITLE & ANALYSIS FOCUS AND DESCRIPTION \\
\hline & $\begin{array}{l}\text { IMPROVING } \\
\text { STUDENTS' } \\
\text { READING } \\
\text { COMPREHENSION } \\
\text { THROUGH } \\
\text { STUDENT TEAMS } \\
\text { ACHIEVEMENT } \\
\text { DIVISIONS (STAD) } \\
\text { TECHNIQUE }\end{array}$ & $\begin{array}{l}\text { Reporting CAR } \\
\text { He reported two different data; quantitative } \\
\text { and qualitative data. To explain the first } \\
\text { data, he provided completely the score } \\
\text { students achieved from Cycle I until Cycle II. } \\
\text { It's also categorized from the highest level to } \\
\text { the lowest one based on the test result of } \\
\text { each cycle. Therefore, it's clearly emphasized } \\
\text { the improvement of each cycle viewed from } \\
\text { the quantitative data. } \\
\text { Similar to the previous analysis, qualitative } \\
\text { description has been presented in his } \\
\text { research report. The description of each cycle } \\
\text { is based on the action research stages; 1) } \\
\text { planning; 2) action; 3) observation; and 4) } \\
\text { reflection. Every stage is explained about } \\
\text { what has been carried out by him in } \\
\text { preparation, action, and reflection. } \\
\text { Result of Analysis } \\
\text { In contrary, what has been elaborated in } \\
\text { quantitative data is not reflected in the } \\
\text { process of teaching learning, specifically the } \\
\text { action process and observation. It was } \\
\text { exemplified in the improvement process of } \\
\text { the students' reading comprehension. In line }\end{array}$ \\
\hline
\end{tabular}




NO. RESEARCH TITLE ANALYSIS FOCUS AND DESCRIPTION
with the presentation of quantitative data,
their reading comprehension have been
enhanced from Cycle I to Cycle II, however, it
cannot be verified in the qualitative data
report. For example, how STAD improved
students reading comprehension is not
rationally explained.
Dealing with the irrelevant description,
moreover, it is found that students were
enthusiastic during teaching and learning
process. In fact there is another statement
which can lead to the bias report that they
are noise. It means it is not consistent
between the word enthusiastic and noise.
Another fact shown in this report is that he
needed to motivate the students because it
was the recommendation of Cycle I. However,
the fact showed that he did not even motivate
the students. In other words, he did not fully
implement what has been recommended in
the previous cycle. Therefore, the
improvement of the students reading
comprehension viewed from the qualitative
data report is still doubtful.
Reporting

IMPROVING

STUDENTS'

SPEAKING ABILITY

USING

INFORMATION GAP

TECHNIQUE

\section{Reporting CAR}

It was reported two different data; quantitative and qualitative data. To explain the first data, he provided completely the score students achieved from Cycle I until Cycle II. It's also categorized from the highest level to the lowest one based on the test result of each cycle. Therefore, it's clearly emphasized the improvement of each cycle viewed from the quantitative data.

Similar to the previous analysis, qualitative description has been presented in his research report. The description of each cycle is based on the action research stages; 1) planning; 2) action; 3) observation; and 4) reflection. Every stage is explained about what has been carried out by him in preparation, action, and reflection.

\section{Result of Analysis}

The data in the form of quantitative and qualitative obtained from speaking test result and observation which were conducted in the two cycles. The quantitative data from the 
Marlina, Ramdani, Sri, Action Research: Theory and Practice in English...

\section{NO. RESEARCH TITLE ANALYSIS FOCUS AND DESCRIPTION}

first cycle showed that the improvement of students' speaking ability was still low. It was described that most of the students got score under 70 and there were only seven students who reached criteria of minimum completion. It means that the students' indicators of speaking were still low. In the second cycle, all of the students reached criteria of minimum completion.

Regarding to the speaking test result from the first to the second cycle, it was not clearly clarified how all students could reach the criteria of minimum completion.

Meanwhile the qualitative data clarified that in the first cycle, there were some strengths and weaknesses appeared. The strengths were clarified that the students were active in responding and asking the question to the teacher, the teacher did the steps of teaching and learning well and she gave the material based on the students' needs. Meanwhile, the weaknesses described in the first cycle are, such as, the researcher didn't manage the time effectively, the students' didn't pay attention while learning, and the students were still confused with the rules of the technique the teacher/researcher used. In the second cycle, the researcher argued that all of the weaknesses emerged in the first cycle had been overcome.

IMPROVING

STUDENTS'

SPEAKING ABILITY

USING ROLE PLAY

TECHNIQUE

\section{Reporting CAR}

This research report is presented systematically, the researcher described the situation before the CAR was implemented, the cycle (consisting two cycles) when implementing CAR, and the result after implementing CAR consisting the result of speaking test and observation and also showing some strengths and weaknesses revealed when each cycle was implemented. Besides, she clarified some recommendation to do for doing the better steps.

\section{Result of Analysis}

After analyzing the data, it is obtained that this research has reported the research result appropriately. The researcher focused not only on the result of quantitative data 


\section{NO. RESEARCH TITLE ANALYSIS FOCUS AND DESCRIPTION}

but also on the result of qualitative data even though she missed enquiring data which encouraged the students' responses about the implementation of role play in speaking class. Further, she explained how the students' problems in speaking can be overcome by using this technique

Based on the table 4.4. it has a clarity that all studies were presenting the quantitative data rather than the qualitative one. Action researcher is necessary to report both quantitative and qualitative data, as opposed to experimental study providing merely the quantitative one. Further, qualitative data must be fleshed out in order that the improvement of each cycle is clearly drawn. What has been carried out from the three studies has the similar way to present the report. They made the effort to provide both quantitative and qualitative data.

The fact shown in their studies is that the qualitative data did not represent what has been described in the quantitative one. For instance, the first study in the above table cannot provide clear information how the improvement occurred in detail from cycle I to cycle II. It cannot be seen how all problem indicators are improved by particular technique. They thought, by showing score only as the progress is sufficient. It is similar to the second study explained in the previous table. It means the result of their studies is still doubtful and is necessary to be reviewed again. The third study is different in which the process how all indicators are enhanced is rationally pointed out. Therefore, what has been reported, specifically in the qualitative data, is irrelevant compared to the quantitative one, except the third study.

The other investigation, interview, has been carried out to receive the other essential evidence for this study. The interview was done with one of the three studies supervisor. It was surprising that the second researcher did not fully understand the concept of action research. In addition, the solution proposed, choosing the technique, is insufficiently understood. It can be seen from the following evidence. 
Marlina, Ramdani, Sri, Action Research: Theory and Practice in English... research."

"I think he has a good capability, but he does not know a lot about action

"In my opinion, to focus on the quantitative data as the progress from cycle I to cycle II is sufficient."

It is clear that the parameter for the researcher as the criteria of success to conduct action research is change of score from one cycle to the next cycle.

Another cause unexpectedly occurred during the interview section. The evidence is as follows,

"I cannot blame my students when he made incomplete report. It's also caused by me in which I do not know the concept of action research comprehensively because of lack of reading"

It means that the supervisor also did not read a lot about action research. She informed what she has known. In relation to this phenomenon, it is significantly essential for the supervisor to find out more information about the research conducted by her student. Therefore, it is really essential to build the literacy among the teachers and students. It aims at avoiding the miss conception toward the research that will be done by the students as the final project.

Dealing with the issue addressed about action research in pre-service teacher, all studies portrayed only quantitave description as their evidence to show the improvement. However, it had lack of elaboration on how the changes of improvement occured qualitatively. Both teacher as supervisor and student-teacher were necessary to surf digitally toward the development of action research particularly or other research designs with the purpose of better implementation of research design in higher education.

\section{Discussion}

The aim of action research conducted by each researcher is to improve he students' particular skill, speaking and reading. The problem indicators occurring are overcome by selecting the accurate technique or method. To propose the solution in conducting action research plays the essential part because it must be rationally explained how all problem indicators are improved by technique or method chosen. 


\section{EduLite}

Journal of English Education, Literature, and Culture

What has been captured from the three studies' background is in line with what has been proposed by the experts. Burns (1999: 293) says action research is defined as the application or process of fact findings to practical problem solving in social situation and education with view to improve the quality of action within involving the collaboration and cooperation of researchers, practitioners and laymen (Burns, 1999: 293; Mertler in Ary, 2010: 514). In other words, collaboration is necessary implemented to meet the quality of improvement for their practice. It is carried out in the process of pre-research, while research, and post research. Viewed from the analysis result, the pre service teachers only collaborated while action research is conducted and evaluation. They seemed not to collaborate holistically in the pre-research, including the selection of particular technique as the solution.

Action research is self-reflective enquiry' undertaken by participants in order to improve the rationality and justice of their own social or educational practices as well as their understanding of these practices and the situations in which these practices are carried out (Carr and Kemmis in Burns, 2010: 5). In contrary, what has been proposed in the studies conducted by pre service teachers are not rationally explained how all indicators are improved by the designated technique or method. This might be an issue which needs to be informed so that there will be a better implementation of action research for them. In addition, it can also be further analyze why pre service teachers chose action research as their project not other types of research.

The idea to change or enhance the condition explained in the three studies is also relevant to the theorists' perspectives. Action research, on the other hand, is carried out by people who want to do something, to evaluate and to change in order to improve their own situation in educational practice (Sagor, 1992: 7; Bassey in Koshy, 2005: 8). What has been found meets the synchronized purpose toward action research. As a result, action research helps teacher or practitioner, in this case pre service teacher, develop their professional development.

The above description has a clarity that action research is done to evaluate in order to change or improve the situation in education practice. It also involves a social situation with the view to improving the quality of action 
Marlina, Ramdani, Sri, Action Research: Theory and Practice in English...

in it (Elliot in Koshy, 2005: 5). The process of action research itself is different from the other research. It can be identified as what has been proposed that action research is a flexible spiral process allows action (change, improvement) and research (understanding, knowledge) to be achieved at the same time (Dick, 2002). To evaluate cannot be implemented without any data. The data collections are received by some strategies which are obtained from observation done by collaborator, written responses or interviews with the students, and test. It is categorized as the three E's; experiencing (observation, enquiring (written responses, interview, etc.), and examining (test) (Mills in Ary, 2010: 525). The all studies conducted by the pre service teachers only did two of them, experiencing and examining. Therefore, they did not comprehensively evaluate the process of teaching and learning. It can be done by building literacy among teachers and students to receive the ample knowledge and information concerning how research is carried out both systematically and accurately.

Action research is carried out systematically through specific stages. Stringer (2008) classifies the stages of the action research into three; look, think, and act. The 'look' stage involves gathering information and data, the 'think' is analyzing the information and reflecting the findings, and the 'act' is implementing the solutions. It is also relevant to other description about stages of action research in which the specific issues are carefully and systematically done through planning, acting, evaluating, refining and learning from the experience to examine the educational practice. It is a continuous learning process in which the researcher learns and also shares the newly generated knowledge with those who may benefit from it (Koshy, 2005: 9; Eileen Ferrance, 2000: 1). Different from the previous paragraphs in which comprehensively analysis and implementation are not done, the pre service teachers followed all stages of action research. It was initially started by planning and completed by reflection.

There is also the other fact shown which has the contrast condition. The change or improvement based on the data analysis can only be seen clearly from the quantitative data. The process of the improvement is not well elaborated even irrelevant. It is opposed to the real concept of action research. 


\section{EduLite}

Journal of English Education, Literature, and Culture

It is conducted naturally occurring settings, primarily using methods common qualitative research (Nunan in Burns, 1999: 24). It has the vibrant notion that exploring qualitative data has to be done in doing the action research. Process orientation is drawn to provide broad evidences on how the problems appeared and are solved rationally.

The progress can be seen through each cycle organized by the action researchers. Ary, et al (2010: 513) state that action research emphasizes a systematic research approach that is cyclical in nature, alternating between action and reflection, continuously refining methods and interpretations based on understandings developed in earlier cycles. The idea of action research is also driven by practical actions from which theories about learning and teaching can be drawn (Burns, 1999: 31).

What can be seen in the studies is only from the test result as the progress. They cannot explore and elaborate the qualitative data to be the strong evidence on how the improvement occurred. Further, the change of condition can be done by reflection providing recommendation of some practical ideas to remedy the previous cycle. Action research is reflective as it aims to bring about the change and improvement in practice (Burns, 1999: 30). However, there is one of the studies which did not implement what has been reflected (see table 4.4 no 1 p. 19). The change of action research by pre service teachers is unconvinced based on the finding because reflection is not carefully analyzed which leads to the inconsistent result of hypothesis action testing. Therefore, the mind set for them is only the improvement of score without any elaboration of complete process as the evidence.

Likewise, action research is really beneficial to carry out for practitioner because it involves continuous evaluation and modifications, and the study can lead to open-ended outcomes. Hence, through action research, the researcher can bring a story to life (Koshy, 2005). In other words, to bring story to life needs deep analysis so that it can be expanded thoroughly.

To pilot action research needs broad understanding on how it is initially commenced, who involves, and how the characters are. Burns (1999: 30) suggests four important points of it, as follows, 
Marlina, Ramdani, Sri, Action Research: Theory and Practice in English...

1. Action research is contextual, small-scale and localized - it identifies and investigates problems within a specific situation.

2. It is evaluative and reflective as it aims to bring about the change and improvement in practice.

3. It is participatory as it provides for collaborative investigation by teams of colleagues, practitioners and researchers.

4. Changes in practice are based on the collection of information or data which provides the impetus for change.

It means action research or all pedagogy is like politics, localized which aims to change the situation, changing the way do, or solve problems occuring in particular contexts. It can be conducted individually or collaboratively.

To sum up the notion of action research, the action researchers, particularly pre service teachers and supervisors, are demanded to comprehend how to initiate the research in the background of the study providing real condition as well as proposing solution rationally. It is achieved by building literacy among them. Besides, it is done collaboratively following action research stages supported by data collection. It is obtained through three different angles; teacher, students, and class condition. Finally, the exploration of qualitative data has to be considered offering comprehensive facts of each cycle progress.

\section{CONCLUSION AND SUGGESTION}

This study aims at analyzing the phenomenon of how pre service teachers carry out classroom action research as their final project. Having analyzed the whole documents of the pre service teachers and other data source, the results indicated that the pre service teachers did not comprehend holistically the notion of action research. Background of the study was not elaborated completely showing evidences of the study. It is also unclear how all problem indicators are improved rationally using particular techniques or method. They did not also comprehensively collect and analyze the data. The last point to emphasize is reporting the research project focusing only in the quantitative data rather than qualitative one. Therefore, both researchers and supervisors are necessary to possess the whole understanding toward the type 


\section{EduLite}

Journal of English Education, Literature, and Culture

Volume 1, Number 2, August 2016

of the research chosen. Enriching literature reviews will enhance the literacy in order to achieve a better implementation in conducting particular research.

\section{REFERENCES}

Anna, Uhl Chamot, Sarah Barnhardt, and Susan Dirstine. (1998). Conducting Action Research in the Foreign Language Classroom. Northeast Conference; New York.

Ary, Donald, et al. (2010). Introduction to Research in Education. Wadsworth: Cengage Learning

Burns, Anne. (1999). Collaborative Action Research for English Language Teacher. Cambridge: Cambridge University Press.

Burns, Anne. (2010). Doing Action Research in English Language Teaching, A Guide for Practicioners. New York: Routledge.

Dick, Bob. (2002). Action Research: Action and Research. retrieved from http://www.aral.com.au/resource/aandr.html

Ferrance, Eileen. (2000). Action Reseach. Northeast and Islands Regional Educational Laboratory At Brown University. Brown University

Koshy, Valsa. (2005). Action Research for Improving Practice a Practical Guide. California: SAGE Publications Inc.

Lattimer, Heather. (2012). Action Research in Pre-Service Teacher Education: is There Value Added?. Inquiery in Education: 3 (1). University of San Diego.

Levin, Barbara B., and Tracy C. Rock. (2003). The Effect of Collaborative Action Research on Preservice and Experienced Teacher Partners in Professional Development Schools.

Sagor, Richard. (1992). How to Conduct Collaborative Action Research. Beauregard: ASCD.

Stringer, Ernest T. (2008). Action Research. Singapore: Sage Publication.

Yin, R. K. (2003). Case study research: Design and Methods (3rd ed.). Thousand Oaks, CA: Sage. 